\title{
A defensin from clam Venerupis philippinarum: Molecular characterization, localization, antibacterial activity, and mechanism of action
}

\author{
Linbao Zhang a,b,c,1, Dinglong Yang a,b,d,1, Qing Wang a,b, Zeyi Yuan e , Huifeng Wu a,b,*, \\ Dong Pei ${ }^{\mathrm{a}, \mathrm{b}}$, Ming Cong ${ }^{\mathrm{a}, \mathrm{b}}$, Fei Li ${ }^{\mathrm{a}, \mathrm{b}}$, Chenglong Ji ${ }^{\mathrm{a}, \mathrm{b}}$, Jianmin Zhao ${ }^{\mathrm{a}, \mathrm{b}, * *}$

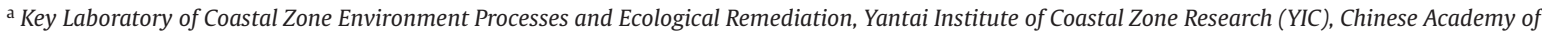 \\ Sciences (CAS), Yantai, China \\ b Shandong Provincial Key Laboratory of Coastal Zone Environmental Processes, YICCAS, Yantai 264003, China \\ c South China Sea Fisheries Research Institute, Chinese Academy of Fishery Sciences, Guangzhou 510300, China \\ d University of Chinese Academy of Sciences, Beijing 100049, China \\ e National Marine Data and Information Service, Tianjin 300171, China
}

\section{A R T I C L E I N F O}

\section{Article history:}

Received 16 September 2014

Revised 11 February 2015

Accepted 11 February 2015

Available online 16 February 2015

\section{Keywords:}

Venerupis philippinarum

Defensin

Molecular characterization

Tissue distribution

Antimicrobial activity

Membrane lesions

\begin{abstract}
A B S T R A C T
Antimicrobial peptides (AMPs) are important mediators of the primary host defense system against microbial invasion. In the present study, we cloned and characterized a member of the invertebrate defensin from the clam Venerupis philippinarum, designated VpDef. Amino acid sequence analysis showed that VpDef was similar to defensins from marine mollusks and ticks. In non-stimulated clams, RT-PCR and immunohistochemical analysis revealed that both VpDef mRNA and the encoding peptide were constitutively expressed in hemocytes and mantles, as well as in other major tissues. VpDef transcripts were significantly induced in hemocytes at different time intervals post Vibrio anguillarum infection. The recombinant VpDef (rVpDef) showed the highest activity against Gram-positive bacteria Micrococcus luteus and less effective to Gram-negative bacteria. In addition, incubation of rVpDef with $M$. luteus at $1 \times$ and $3 \times$ MIC could induce an obvious decrease of the membrane potential and notable changes of membrane permeability in a dose-dependent manner. Membrane integrity and bacterial viability analysis also revealed that rVpDef increased the membrane permeability of $M$. luteus and then resulted in cell death at $2 \times$ and $10 \times$ MIC. Overall, these results suggest that VpDef has an important function in host defense against invasive pathogens, probably killing microbes by inducing membrane lesions.
\end{abstract}

(c) 2015 Elsevier Ltd. All rights reserved.

\section{Introduction}

It is widely known that antimicrobial peptides (AMPs) are ubiquitous arsenals of all living organisms for combating against invading pathogens (Zasloff, 2002). The direct antibiotic activity of AMPs is thought to be based on their cationic and amphiphilic nature, which enables these peptides to interact with negatively charged bacterial surfaces and membranes, subsequently causing membrane disruption or altering metabolic processes (Brogden, 2005; Hale and

\footnotetext{
* Corresponding author. Shandong Provincial Key Laboratory of Coastal Zone Environmental Processes, YICCAS, Yantai 264003, China. Tel.: +86 535 2109190; fax: +865352109000.

E-mail address: hfwu@yic.ac.cn (H. Wu).

** Corresponding author. Shandong Provincial Key Laboratory of Coastal Zone Environmental Processes, YICCAS, Yantai 264003, China. Tel.: +86 535 2109170; fax: +865352109000.

E-mail address: jmzhao@yic.ac.cn (J. Zhao).

1 These authors contributed equally to this article.
}

Hancock, 2007). AMPs represent potential substitutes for antibiotics due to their broad specificity against bacteria or fungi, and their anti-viral, anti-tumoral, anti-inflammatory, wound-healing, and immunomodulatory activities (Diamond et al., 2009; Otero-González et al., 2010). Despite being evolutionary ancient, AMPs exhibit great diversity in terms of structural features, biological properties and functions, and also in their tissue distribution and expression profiles (Bachere et al., 2004; Bulet et al., 2004).

To date, over 1500 AMPs have been identified from numerous phylogenetically diverse organisms (Sperstad et al., 2011). Defensins are small cysteine-rich cationic proteins found in both vertebrates and invertebrates (Ganz, 2003; Wong et al., 2007). Generally, mammalian defensins can be grouped into three subfamilies designated $\alpha, \beta$, and the cyclic $\theta$ defensins (Wong et al., 2007). Both $\alpha$ and $\beta$ defensins adopt a triple stranded antiparallel $\beta$-sheet structure, while defensins from invertebrates and plants contain an $\alpha$-helix that is disulphide-linked to an antiparallel two-stranded $\beta$-sheet with a cysteine-stabilized $\alpha$-helix/ $\beta$-sheet motif (CS $\alpha \beta$ ) (Dimarcq et al., 1998). This motif is widespread in arthropod and mollusk defensins 
(Adhya et al., 2012; Bulet and Stocklin, 2005; Gueguen et al., 2006; Yang et al., 2000).

Marine mollusks are constantly exposed to high concentrations of bacteria and viruses (Ammerman et al., 1984), many of which may be pathogenic. In recent years, multiple defensins have been identified from marine mollusks, such as Mytilus galloprovincialis (Hubert et al., 1996), Mytilus edulis (Charlet et al., 1996), Crassostrea virginica (Seo et al., 2005), Crassostrea gigas (Gonzalez et al., 2007; Gueguen et al., 2006), Haliotis discus discus (De Zoysa et al., 2010) and Venerupis philippinarum (Adhya et al., 2012).

Manila clam $V$. philippinarum, one of the most commercially important aquaculture species, has been undergoing mass die-offs caused by unusually high levels of pathogenic species (Park et al., 2006). Hence, understanding the host defense mechanisms of clams has become a primary concern. Previously, a defensin (MCdef) has been identified from Manila clam with the highest microbicidal activity against Streptococcus iniae and Staphylococcus aureus (Adhya et al., 2012). In this work, we report the characterization of a novel defensin from $V$. philippinarum, designated as VpDef. We describe the spatial tissue distribution and temporal expression, as well as the microbial activity and mechanism of action of VpDef. These findings may help shed light on the immune responses of clams, and have implications for disease control in the practice of aquaculture.

\section{Materials and methods}

\subsection{Clams and bacterial challenge}

The clams V. philippinarum (shell length: $3.0-4.0 \mathrm{~cm}$ ) were purchased from a local farm and acclimated for 1 week before commencement of the experiment. They were maintained in seawater ( $30 \%$ salinity) at $20-22{ }^{\circ} \mathrm{C}$ throughout the whole experiment. For the bacterial challenge experiment, the clams were randomly divided into four tanks with 501 capacity, each containing 50 clams. One tank served as the control, while the other three tanks were exposed to high density of $V$. anguillarum with final concentration of $10^{7} \mathrm{CFU} \mathrm{ml}{ }^{-1}$. Five individuals were randomly sampled from each tank at $6,12,24,48,72$ and $96 \mathrm{~h}$ post bacterial challenge. The clams cultured in the normal seawater were used as control group. Hemocytes were harvested from the hemolymph by centrifugation at $2000 \times g, 4{ }^{\circ} \mathrm{C}$ for $10 \mathrm{~min}$.

\section{2. cDNA cloning and sequence analysis of $\mathrm{VpDef}$}

A Manila clam EST homologous to $C$. gigas defensin2 was identified through large scale EST sequencing of the cDNA library constructed from clam hemocytes (Zhao et al., 2010). To generate the full-length cDNA of VpDef, two reverse primers P1 and P2, and two forward primers P3 and P4 (Table 1), were designed based on the EST sequence. The nested PCR strategy was applied to the $3^{\prime}$ and 5' RACE.

The nucleotide sequence was analyzed using the BLAST algorithm at NCBI web site (http://www.ncbi.nlm.nih.gov/blast), and the deduced amino acid sequence was analyzed with the Expert Protein Analysis System (http://www.expasy.org/). The percentage of similarity and identity of VpDef with defensins from other organisms were calculated by the Identity and Similarity Analysis program (http://www.biosoft.net/sms/index.html). Multiple alignments were performed with the ClustalW Multiple Alignment program (http://www.ebi.ac.uk/clustalw/) and Multiple Alignment Show program (http://www.bio-soft.net/sms/index.html). A neighborjoining phylogenetic tree was constructed by MEGA 4.0 with 1000 bootstrap replicates.
Table 1

Primers used in the present study.

\begin{tabular}{lll}
\hline Primer & Sequence $\left(5^{\prime}-3^{\prime}\right)$ & Sequence information \\
\hline P1 & TGGTGCTGTGATGAGTTCTAT' & 5' RACE primer \\
P2 & TGCACCTCTGACGTAATGT & 5' RACE primer \\
P3 & GGTTTGGTTGCCCTGAAGAGA & 3' RACE primer \\
P4 & GAACTCATCACAGCACCAACA & 3' RACE primer \\
P5 & GAGGACGATGATTGCTTTACTG & Genomic clone primer \\
P6 & ACTTGATTGCGTGTTGGTGC & Genomic clone primer \\
P7 & CAACAGGTTTAGCACTCAACGG & Tissue distribution detection primer \\
P8 & AAACTTGCTTGCGTGTTGGTGC & Tissue distribution detection primer \\
P9 & CTCCCTTGAGAAGAGCTACGA & $\beta$-Actin primer \\
P10 & GATACCAGCAGATTCCATACCC & $\beta$-Actin primer \\
P11 & GCCCTGAAGATGAATATGAG & Real-time PCR \\
P12 & TGTTGGTGCTGTGATGAGTT & Real-time PCR \\
P13 & CATATGGGGTTTGGTGCCCTG & Recombinant primer \\
& AAGA & \\
P14 & CTCGAGCTAGTGGTGGTGGTGG & Recombinant primer \\
& TGGTGTTCTTGAATAGATCTCC & \\
\hline
\end{tabular}

a A Nde I site was added to the 5' end of primer13.

b A Xho I site was added to the 5' end of primer 14 after the stop codon, and six histidine coding sequence was insert before the stop codon.

\subsection{VpDef $m R N A$ expression in different tissues and the response to $\mathrm{V}$. anguillarum challenge}

The tissue-specific expression profile of VpDef mRNA was assayed by semi-quantitative RT-PCR. Total RNA was extracted from different tissues of four individuals, including hemocytes, mantles, gills, hepatopancreas and adductor muscles. Gene-specific primers (P5 and P6) and $\beta$-actin primers (P7 and P8) were listed in Table 1. PCR was optimized by performing different cycle numbers $(n=22,24$, 26,28 , and 30) to avoid the PCR saturation. After the optimization step, PCR with 26 cycles were selected for VpDef and 23 cycles for $\beta$-actin. The PCR products were separated on $1.5 \%$ agarose gel and stained with ethidium bromide.

The expression of VpDef transcript in hemocytes after Vibrio challenge was measured by quantitative real time RT-PCR in Applied Biosystem 7500 fast Real-time PCR System. Gene-specific primers (P9 and P10) and $\beta$-actin primers (P7 and P8) were listed in Table 1. The PCR was carried out in a total volume of $50 \mu \mathrm{l}$, containing $25 \mu \mathrm{l}$ of SYBR Green PCR Master Mix (Applied Biosystems), $20 \mu \mathrm{l}$ of the diluted cDNA, $0.5 \mu \mathrm{l}$ of each of primers $(10 \mu \mathrm{mol} / \mathrm{l})$, and $4 \mu \mathrm{l}$ of DEPCtreated water. The thermal profile for RT-PCR was $50{ }^{\circ} \mathrm{C}$ for $2 \mathrm{~min}$ and $95^{\circ} \mathrm{C}$ for $10 \mathrm{~min}$ followed by 40 cycles of $95^{\circ} \mathrm{C}$ for $15 \mathrm{~s}$ and $60{ }^{\circ} \mathrm{C}$ for $31 \mathrm{~s}$. After amplification, data acquisition and analysis were performed using the Sequence Detection Software (SDS 2.3, Applied Biosystems). The $2^{-\Delta \Delta c t}$ method was chosen as the calculation method (Kenneth and Thomas, 2001). All datasets were given in terms of relative mRNA expression as means \pm standard deviation. Oneway analysis of variance (ANOVA) was performed on all data using SPSS 13.0 statistical software, and $P$ values less than 0.05 were considered statistically significant.

\subsection{Recombinant expression and mass spectrometric analysis of rVpDef}

Recombinant VpDef peptide (rVpDef) was obtained according to the method described previously with minor modifications (Zhao et al., 2010). The mature peptide of VpDef was amplified with genespecific primers P11 and P12 with Nde I and Xho I sites at their 5' end, respectively (Table 1). rVpDef was expressed in Escherichia coli Origami (DE3) (Novagen) as a C-terminal His6-tagged fusion protein using the pET-30a(+) system (Novagen). Expression, purification and refolding of rVpDef were performed according to the methods described previously (Wang et al., 2012). In the present study, the rVpDef was expressed as inclusion bodies and purified by HisTrap 
Chelating Columns under denatured conditions. The purified protein was refolded in gradient urea-TBS glycerol buffer $(50 \mathrm{mM} / \mathrm{l}$ Tris$\mathrm{HCl}, 50 \mathrm{mM} / 1 \mathrm{NaCl}, 10 \%$ glycerol, $2 \mathrm{mM} / 1$ reduced glutathione, $0.2 \mathrm{mM} / 1$ oxide glutathione, a gradient urea concentration of 6,5 , $4,3,2,1,0 \mathrm{M} / 1$ urea in each gradient, $\mathrm{pH} 8.0$; each gradient at $4{ }^{\circ} \mathrm{C}$ for $12 \mathrm{~h}$ ). Purified rVpDef was boiled for 5 minutes, and then analyzed by $15 \%$ SDS-PAGE under reducing conditions. Following electrophoresis, polyacrylamide gels were stained with Coomassie brilliant blue R250.

The target protein band was excised from the gel and digested with trypsin as previously described (Wilm et al., 1996). The digested solution was vacuum-dried, dissolved with $0.1 \%$ formic acid in 50\% acetonitrile (v/v) and analyzed by LC-ESI-MS/MS. The MS/ MS spectra were searched with BioWorks 3.1 software, using the SEQUEST algorithm.

\subsection{Antibody preparation and immunodetection of VpDef}

Two male rabbits were purchased from the State Institute for Drug Control (Qingdao, China) and immunized with rVpDef to acquire polyclonal antibody as described previously (Cheng et al., 2006). The antibody specificity was evaluated by western blot. Lysates of $E$. coli (transformed with plasmid pET-30a-VpDef and induced by IPTG) incubated with the anti-rVpDef antibody showed a single band in the PVDF membrane, indicating the specificity of the antibody.

The slides of hemocytes were prepared according to previously published procedures and fixed in acetone for $15 \mathrm{~min}$ (Yang et al., 2011). The gills, mantles, adductor muscles and hepatopancreas were dissected and fixed in $4 \%$ buffered paraformaldehyde solution, dehydrated in ethanol, embedded in paraffin and sectioned at $6 \mu \mathrm{m}$. The slides of hemocytes and tissues were incubated in a moisture chamber at $37^{\circ} \mathrm{C}$ for $1 \mathrm{~h}$ with rVpDef antibody (diluted 1:5000 in PBS-T). After washing three times with PBS-T, the slides were incubated at $37^{\circ} \mathrm{C}$ for $1 \mathrm{~h}$ with alkaline phosphatase-conjugated goat anti-rabbit IgG (Zhongshan, China) diluted at 1:200 with PBST. The slides were washed three times with PBS-T, visualized using an AP-Red Assay Kit (Zhongshan, China), and counter stained with hematoxylin. The localization of VpDef was recorded by phasecontrast microscopy (Olympus). Positive signal was stained red and the other signals were stained blue. Rabbits' pre-immune serum was used as negative control.

\subsection{Antimicrobial activity of rVpDef}

Antibacterial testing of rVpDef and ampicillin was carried out using two Gram-positive bacteria (Staphyloccocus aureus and $M$. luteus) and eight Gram-negative bacteria (V. anguillarum, Entherobacter cloacae, Pseudomonas putida, Proteus mirabilis, Enterobacter aerogenes, $V$. parahaemolyticus, $V$. splendidus and $V$. harveyi). The minimal inhibitory concentration (MIC) was determined according to the method of Hancock (Amsterdam, 1996). The assay was done in triplicate in three independent experiments. The MIC value was recorded as the range between the highest concentration of the protein where bacterial growth was observed and the lowest concentration that caused 100\% inhibition of bacteria growth. The concentration of rVpDef was measured by BCA Protein Assay Kit (Beyotime, China).

\subsection{Time-killing kinetics of VpDef}

M. luteus cells were grown in LB broth to exponential phase, harvested by centrifugation, washed twice with $10 \mathrm{mM}$ sodium phosphate buffer ( $\mathrm{pH}$ 7.4) and re-suspended in the same buffer. Approximately $2 \times 10^{7}$ cells were incubated at $37{ }^{\circ} \mathrm{C}$ with $10 \times$ MIC of rVpDef or PBS (control). Aliquots $(10 \mu \mathrm{l})$ were withdrawn at $0,0.5$, $1,2,4,6,10,20 \mathrm{~h}$, diluted 10-fold and plated onto the LB-agar. After overnight incubation at $37^{\circ} \mathrm{C}$, the number of surviving bacteria, expressed as CFU (colony-forming units), were counted and the timekill curves were plotted with time against the logarithm of the viable count. Triple independent experiments were performed for timekilling kinetics.

\subsection{Bacterial viability and membrane integrity}

M. luteus cells were prepared as indicated in Section 2.7, incubated with $2 \times$ and $10 \times$ MIC of rVpDef at $37^{\circ} \mathrm{C}$ for $1 \mathrm{~h}$, poured onto poly-L-lysine-treated glass slides, and then kept at $37^{\circ} \mathrm{C}$ for $45 \mathrm{~min}$ to allow the adhesion of cells to the slides. Subsequently, the slides were washed with PBS, and incubated with FITC ( $6 \mu \mathrm{g} \mathrm{ml}^{-1}$ in PBS, Sigma-Aldrich) and 5-cyano-2, 3-ditolyl tetrazolium chloride (CTC, $5 \mathrm{mM}$ in PBS, Sigma-Aldrich) solution at $37^{\circ} \mathrm{C}$ for $1 \mathrm{~h}$, respectively. In all cases, PBS was used as negative control. After that, phase contrast images as well as images under fluorescence light were recorded using an Olympus BX51 fluorescence microscope.

\subsection{Determination of bacterial membrane potential and permeability by flow cytometry}

M. luteus cells were prepared as indicated in Section 2.7, and diluted in PBS ( $\mathrm{pH} 7.4$ ) buffer to the concentration of $10^{6}-10^{7}$ cells/ $\mathrm{ml}$. Flow cytometry was used to detect red $(590-630 \mathrm{~nm})$ fluorescence associated with aggregates of 3, 3'diethyloxacarbocyanine iodide (DiOC2(3)) (Molecular Probes, USA), which, in the monomeric state, is normally green $(488-530 \mathrm{~nm})$ fluorescent. The red fluorescence of DiOC2(3) increases with the interior negative membrane potential (MP) gradient, indicating the dye accumulation in bacteria with active MP. The green fluorescence from stained bacteria is dependent on bacteria size but independent of MP. The ratio of red to green fluorescence provides an accurate and precise measurement of bacterial MP (Novo et al., 1999). In addition, the far-red $\left(>695 \mathrm{~nm}\right.$ ) fluorescence of TO-PRO ${ }^{\circledR}-3$ iodide (Molecular Probes, USA) was used to demonstrate membrane permeability. TO-PRO-3 is generally excluded by prokaryotic and eukaryotic cells with intact cytoplasmic membranes. Therefore, the ratio of TO-PRO-3 fluorescence to $\mathrm{DiOC2}$ (3) green fluorescence produces a normalized indicator of membrane permeability (Novo et al., 2000).

After exposure to rVpDef at $1 \times$ and $3 \times \mathrm{MIC}$ for $30 \mathrm{~min}$ at $37^{\circ} \mathrm{C}$, the cells were incubated with $30 \mu \mathrm{M} \mathrm{DiOC}(3)$ and $100 \mathrm{nM}$ TOPRO-3 at room temperature for $10 \mathrm{~min}$. PBS was used as negative control and the pore-forming lantibiotic nisin $\mathrm{Z}(1.5 \mu \mathrm{g} / \mathrm{ml}$ corresponds to $1 \times$ the MIC, Sigma-Aldrich) was used as positive control. Flow cytometric studies were performed according to the method described by Novo et al. (2000).

\subsection{SEM experiment}

M. luteus cells were grown, treated with $2 \times$ and $10 \times$ MIC rVpDef for $1 \mathrm{~h}$ at $37^{\circ} \mathrm{C}$, and immobilized on poly-L-lysine-treated glass slides as indicated in the previous section. Slide-immobilized cells were fixed with $2.5 \%(\mathrm{w} / \mathrm{v})$ glutaraldehyde in $0.1 \mathrm{M}$ sodium phosphate buffer for $30 \mathrm{~min}$ and dehydrated with a graded ethanol series. After critical-point drying and gold coating, the samples were visualized by Hitachi S-4800 instrument.

\section{Results}

\section{1. cDNA cloning and sequence analysis of $\mathrm{VpDef}$}

A 410 bp fragment representing the complete cDNA sequence of $V p D e f$ was deposited in the GenBank database under the accession no. HQ329097. The complete coding sequence of VpDef was 
1 \begin{tabular}{lllllllllll}
$M$ & $R$ & $T$ & $M$ & $I$ & $A$ & $F$ & $T$ & $V$ & $F$ & I \\
\hline
\end{tabular}

1 caacaggtttagcact caacggegaaaATGAGGACGATGATTGCTTTTACTGTTTTTATC $\begin{array}{llllllllllllllllllllll}12 & \mathrm{~L} & \mathrm{~L} & \mathrm{~A} & \mathrm{~A} & \mathrm{M} & \mathrm{F} & \mathrm{L} & \mathrm{Q} & \mathrm{D} & \mathrm{V} & \mathrm{D} & \mathrm{A} & \mathrm{G} & \mathrm{F} & \mathrm{G} & \mathrm{C} & \mathrm{P} & \mathrm{E} & \mathrm{D} & \mathrm{E}\end{array}$

61 CTTCTTGCAGCTATGTTTTTGCAAGACGTTGATGCCGGGTTTGGTTGCCCTGAAGATGAA

$\begin{array}{lllllllllllllllllllll}32 & \mathrm{Y} & \mathrm{E} & \mathrm{C} & \mathrm{H} & \mathrm{N} & \mathrm{H} & \mathrm{C} & \mathrm{K} & \mathrm{N} & \mathrm{S} & \mathrm{V} & \mathrm{G} & \mathrm{C} & \mathrm{R} & \mathrm{G} & \mathrm{G} & \mathrm{Y} & \mathrm{C} & \mathrm{D} & \Lambda\end{array}$

121 TATGAGTGCCACAACCATTGTAAAAATTCAGTCGGTTGTAGGGGCGGCTATTGTGATGCC

$\begin{array}{llllllllllllllllllllll}52 & \mathrm{G} & \mathrm{T} & \mathrm{L} & \mathrm{R} & \mathrm{Q} & \mathrm{R} & \mathrm{C} & \mathrm{T} & \mathrm{C} & \mathrm{Y} & \mathrm{G} & \mathrm{C} & \mathrm{N} & \mathrm{Q} & \mathrm{K} & \mathrm{G} & \mathrm{R} & \mathrm{S} & \mathrm{I} & \mathrm{Q}\end{array}$

181 GGGACATTACGTCAGAGGTGCACTTGTTACGGTTGCAACCAAAAAGGGAGATCTATTCAA

$72 \mathrm{E} *$

241 GAATAGaactcatcacagcaccaacacgcaatcaagtttctaacaatctacgaactg tct

301 tattgaactgaaaatatatatatacataaaagaacaatttccaagttattaactccgt

361 tcttacattaaaa tatatctatcttgcaaaaaaaaaaaaaaaaaaaaaaa

Fig. 1. The complete cDNA sequence (below) and deduced amino acid (above) sequence of $V p D e f$. The predicted signal peptide is underlined.

219 bp in length, encoding a polypeptide of 72 amino acids (Fig. 1). The putative signal peptide was identified at the $\mathrm{N}$-terminal sequence with the possible cleavage site between $A^{23}$ and $G^{24}$.

The mature VpDef (49 amino acids) was analyzed using the antimicrobial peptide predictor program (http://aps.unmc.edu/AP/ prediction/prediction_main.php). The results showed that VpDef possessed combined helix and beta structure, and four potential disulfide bonds. VpDef exhibited sequence identities of 32-63\% with defensins from mollusk and tick species. Alignments of VpDef with defensins from mollusk and tick species suggested that the putative disulfide array in VpDef was perhaps conserved, as observed in defensins from the oyster $C$. gigas $\left(C_{1}-C_{5}, C_{2}-C_{6}, C_{3}-C_{7}\right.$ and $C_{4}-C_{8}$ ) (Fig. 2A). Phylogenetic analysis of defensin sequences from mollusk, insect, fish, and mammal species showed that these sequences were split into two major groups, invertebrate and vertebrate defensins (Fig. 2B). The Manila clam defensins (VpDef and MCdef) clustered together with mollusk and tick defensins. In addition, defensins from abalones and other insects formed another cluster of the invertebrate group.

\subsection{Tissue distribution of VpDef and gene expression in response to $\mathrm{V}$. anguillarum challenge}

The tissue distribution of VpDef mRNA transcripts in uninfected clams was analyzed by RT-PCR. VpDef mRNA transcripts were predominantly expressed in hemocytes, moderately in mantles, and marginally expressed in gills and hepatopancreas (Fig. 3A). To confirm the tissue distribution of VpDef peptide, immunohistochemical analysis was performed by using a rabbit polyclonal IgG antibody raised against rVpDef. The specificity of polyclonal anti-VpDef antibody was confirmed by western blot analysis, and the result showed that this antibody reacted specifically with rVpDef (Fig. S1). It was found that VpDef was primarily present in the tissues of hemocytes, mantles, gills and hepatopancreas (Fig. 3B). The signal was much stronger in hemocytes than that in other tissues. VpDef in mantles and gills was concentrated at the epithelial surface, while positive signal was undetectable in adductor muscles of unchallenged clams.

The temporal expression of VpDef transcript in hemocytes of clams post bacterial challenge is shown in Fig. 3C. During the first $6 \mathrm{~h}$ after pathogen challenge, the expression level of VpDef mRNA was increased up to 5.6-fold of the control group $(P<0.05)$. After that, the expression level kept increasing and the highest expression level was detected at $12 \mathrm{~h}$ post-infection, which was 1300 fold higher than the control group $(P<0.05)$. As time progressed, the expression level was markedly decreased at $24 \mathrm{~h}$. However, significant up-regulation of $V p D e f$ expression was again detected at a level 58-fold higher than that of the control group after exposure for $48 \mathrm{~h}(P<0.05)$. After exposure for 72 and $96 \mathrm{~h}$, the expression of $V p D e f$ recovered nearly to the original level (at $0 \mathrm{~h}$ ).

\subsection{Recombinant production and antimicrobial activity of rVpDef}

The His-tagged rVpDef protein was expressed in E. coli, and purified as described in Section 2. Analysis of rVpDef by SDS-PAGE revealed that the peptide possesses a molecular mass less than $14.4 \mathrm{kDa}$ (Fig. 4, lane 3). The molecular mass measured by LC-ESIMS/MS (6492 Da) was in perfect agreement with the predicted molecular masse of rVpDef (6496.16 Da). In addition, one of the peptide fragments -RSIQEHHHHHH- identified by LC-ESI-MS/MS analysis corresponded to the 45-55 of the rVpDef amino acid sequence (data not shown).

The spectrum of antimicrobial activity of rVpDef was investigated against several Gram-positive and Gram-negative bacteria. The rVpDef displayed its microbicidal activity against $M$. luteus, but was less effective against Staphyloccocus aureus and Gram-negative bacteria (Table 2). To examine the mechanism of bacterial growth inhibition of rVpDef in terms of bacteriostatic or bactericidal effects, a time-killing experiment was performed by using the sensitive bacterium M. luteus. When M. luteus was incubated with $10 \times$ MIC of rVpDef, all bacteria were killed within $4 \mathrm{~h}$ (Fig. 5).

\subsection{Bacterial viability and membrane integrity}

FITC is a low-molecular-mass (389.4 Da) green fluorescent probe, which is unable to traverse the cytoplasmic membrane of intact cells and provides an indication of membrane integrity (Mangoni et al., 2004). In the present study, FITC was used as a fluorescence probe to visualize the cytoplasmic membrane-perturbing activity of rVpDef on $M$. luteus. When cells were incubated with FITC in the absence of rVpDef pretreatment, no appreciable fluorescent signal was discerned, as visualized by comparing the phase contrast and fluorescence microscopy images (Fig. 6A and B). In contrast, FITC was readily accumulated in bacteria after their exposure to rVpDef at both 2 and $10 \times$ MIC (Fig. $6 \mathrm{D}$ and F), suggesting that the peptide increases the permeability of the bacterial membrane.

In addition, the redox dye, CTC is a colorless, membranepermeable compound that produces a red-fluorescing precipitate in the cell when it is reduced by the electron-transport chain of bacterial cell. Therefore, CTC can be used as a direct indicator of respiratory activity and viability of bacteria (Smith and McFeters, 1997). In the present study, no red fluorescence was observed in some bacteria (Fig. 7D and F) after treated by rVpDef for $1 \mathrm{~h}$ at both $2 \times$ and $10 \times$ MIC, thus proving that they were dead.

\subsection{Bacterial membrane potential and permeability}

Fig. 8 plotted membrane potential (MP) of rVpDef-treated $M$. luteus against permeability. In cultures treated with PBS (Fig. 8A),

Table 2

Antimicrobial activity of rVpDef by liquid growth inhibition assay.

\begin{tabular}{lcl}
\hline Microorganisms & $\begin{array}{l}\text { MIC value } \\
(\mathrm{rVpDef} \mu \mathrm{M})\end{array}$ & $\begin{array}{l}\text { MIC value } \\
(\text { ampicillin } \mu \mathrm{M})\end{array}$ \\
\hline $\begin{array}{l}\text { Gram-positive bacteria } \\
\text { Staphyloccocus aureus }\end{array}$ & $25-50$ & 2.69 \\
$\quad$ Micrococcus luteus & $6.25-12.5$ & 2.69 \\
Gram-negative bacteria & & \\
Vibrio anguillarum & $25-50$ & 0.34 \\
Enterobacter cloacae & $25-50$ & 0.67 \\
Pseudomonas putida & $25-50$ & \\
Proteus mirabilis & $50-100$ & 0.34 \\
Enterobacter aerogenes & $12.5-25$ & 1.35 \\
Vibrio parahaemolyticus & $>100$ & 2.69 \\
Vibrio splendidus & $50-100$ & 0.67
\end{tabular}

a MIC values were expressed as the range between the highest concentration of the protein where bacterial growth was observed and the lowest concentration that caused $100 \%$ inhibition of bacteria growth $(\mu \mathrm{M})$. 
$\mathbf{A}$

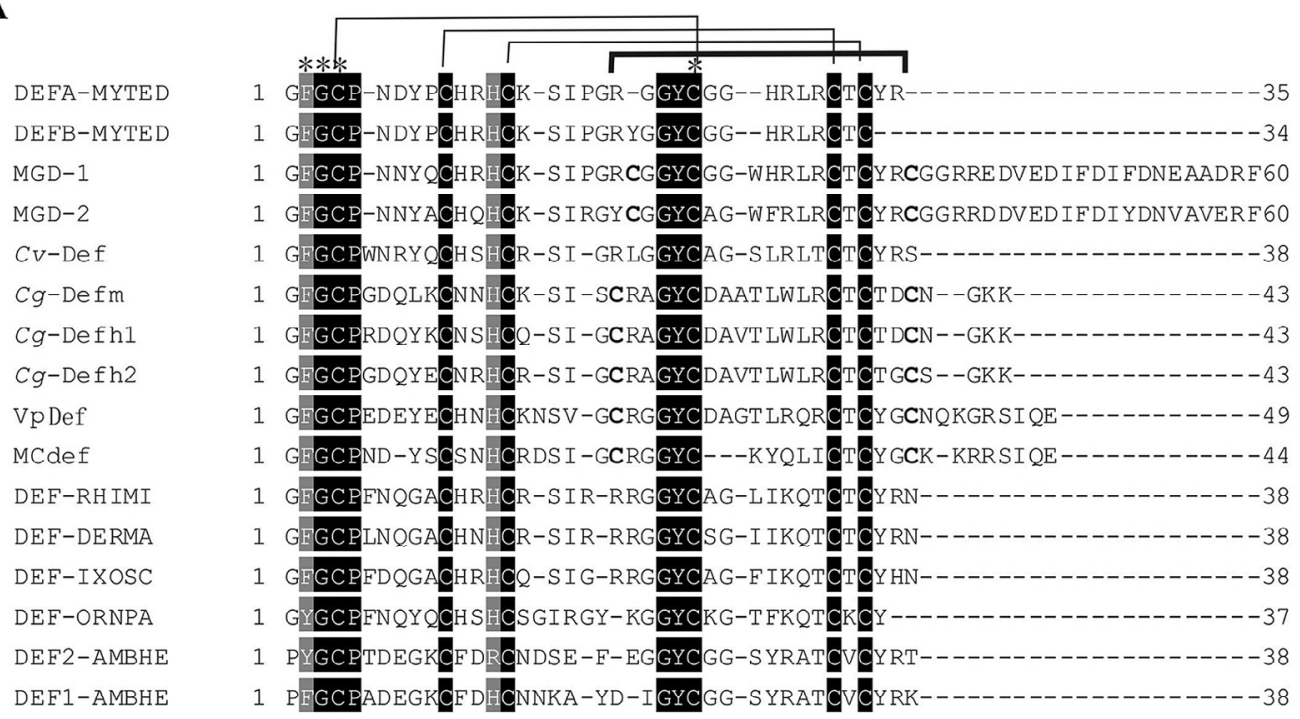

B

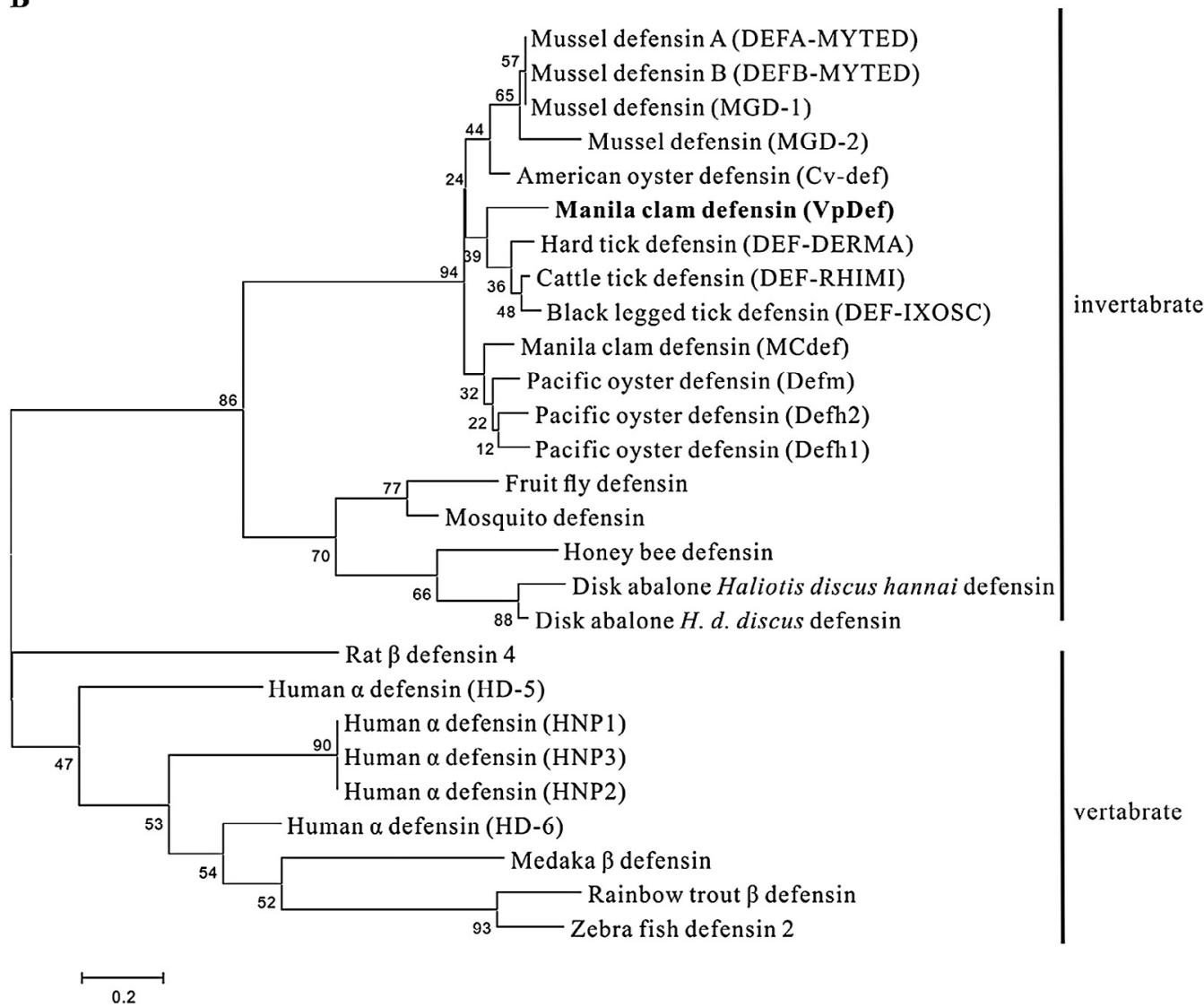

Fig. 2. Comparison of VpDef with other defensins. (A) Amino acid sequence alignment of the mature VpDef sequence and defensins found in other marine mollusks [M. edulis DEFA-MYTED (P81610) and DEFB-MYTED (P81611), M. galloprovincialis MGD-1 (P80571) and MGD-2 (AAD52660), C. gigas Cg-Defh1 (ABD66301), Cg-Defh2 (ABD66302) and Cg-Defm (AEO45009), C. virginica Cv-def (P85008), V. philippinarum MCdef (Adhya et al., 2012)] and ticks [Rhipicephalus microplus DEF-RHIMI (AAO48943), Dermacentor marginatus DEF-DERMA (ACJ04433), Ixodes scapularis DEF-IXOSC (AAV80792), Ornithodoros papillipes DEF-ORNPA (ACJ04425), Amblyomma hebraeum DEF2-AMBHE (AAR97291) and DEF1-AMBHE (AAR97290)]. The two additional cysteines are in bold. Asterisks indicate amino acids conserved in oyster defensin and plectasin that are involved in the defensin-lipid II interaction (Schmitt et al., 2010; Schneider et al., 2010). (B) A phylogenetic tree constructed by the neighbor-joining method. Numbers at tree nodes indicate the bootstrap confidence values from 1000 replicates. The accession numbers are mussel defensin A (P81610), defensin B (P81611), MGD-1 (P80571) and MGD-2 (AAD52660): Pacific oyster Defh1 (ABD66301), Defh2 (ABD66302) and Defm (AE045009); American oyster defensin (P85008); Manila clam MCdef (Adhya et al., 2012); black legged tick defensin (AAV80792); cattle tick defensin (AAO48943); hard tick defensin (ACJ04433); fruit fly defensin (NP_523672); mosquito defensin (Q17027); honey bee defensin (ACH96385); disk abalone Haliotis discus hannai defensin (ABF69125) and H. discus hannai (ACZ15982); rat $\beta$ defensin 4 (NP_071989); human $\alpha$ defensin HD-5 (NP_066290); human $\alpha$ defensin HNP1 (NP_004075); human $\alpha$ defensin HNP3 (AAA35753); human $\alpha$ defensin HNP2 (P59666); human $\alpha$ defensin HD-6 (NP_001917); medaka $\beta$ defensin (ACG55699); rainbow trout $\beta$ defensin (ABR68250) and zebra fish defensin 2 (CAJ57442). 
$\mathbf{A}$

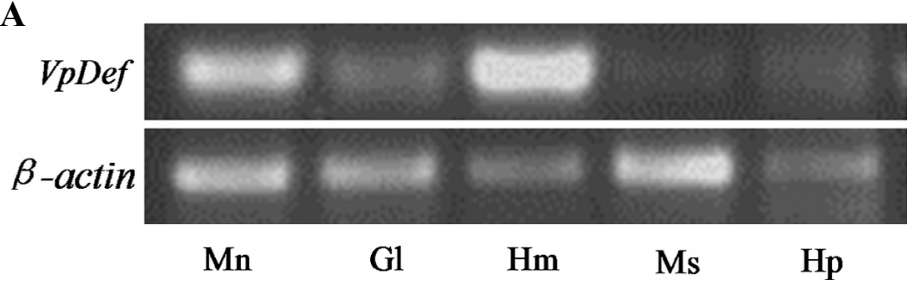

B

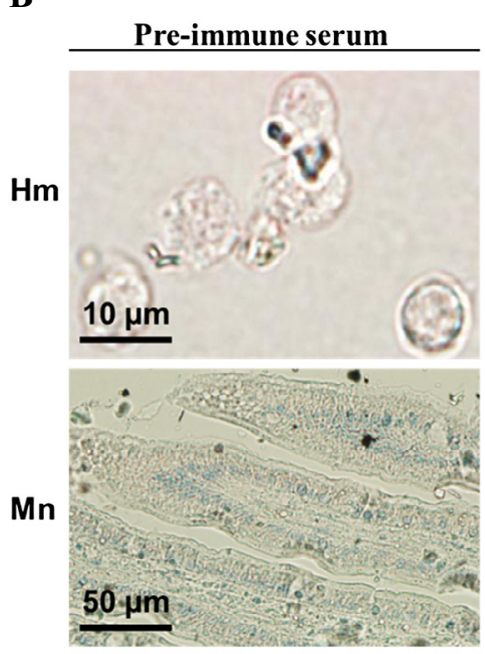

GI
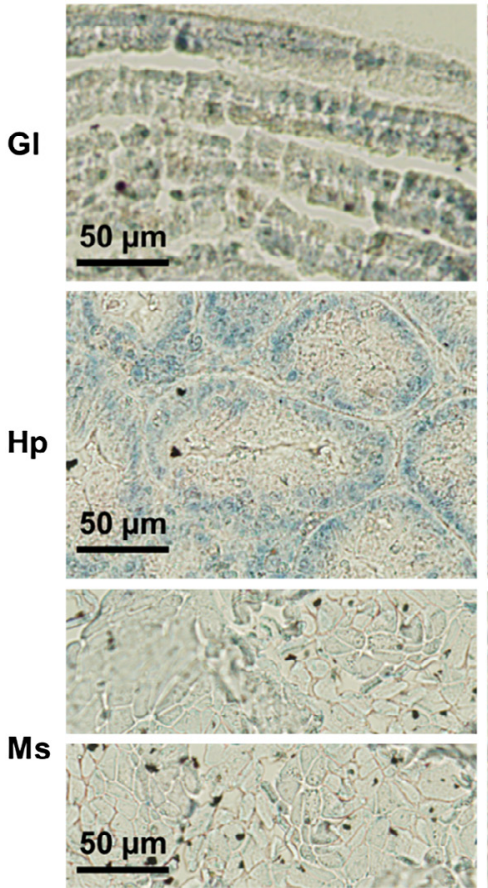

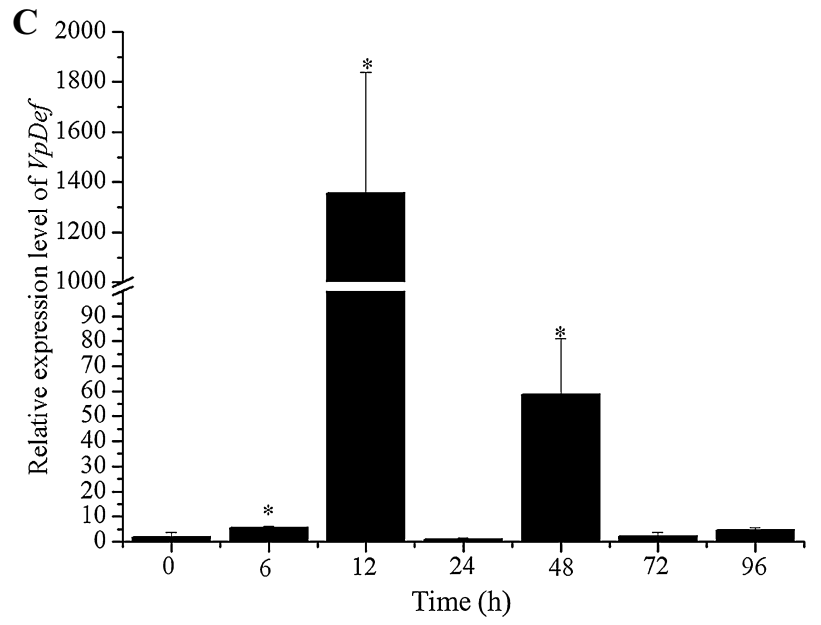

rVpDef antiserum
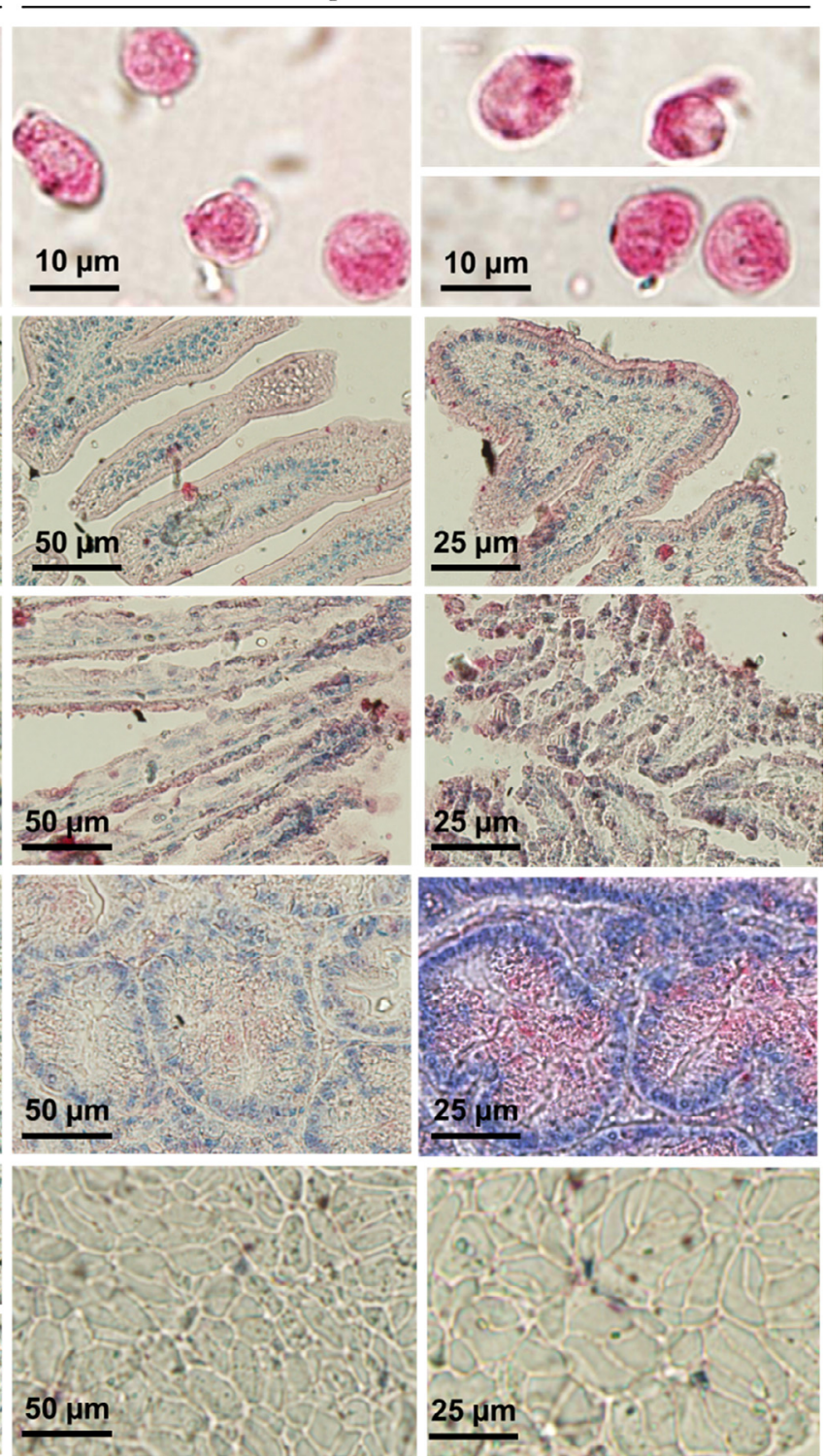

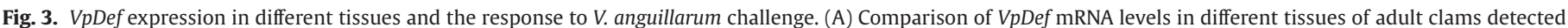

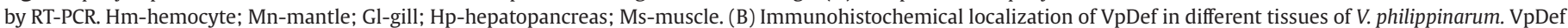

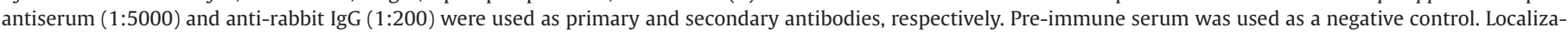

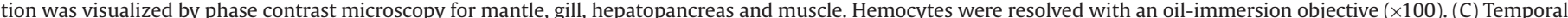

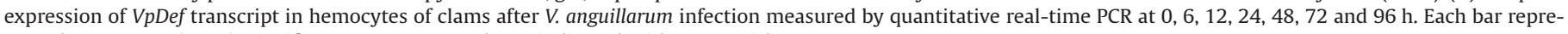
sented mean \pm S.D $(n=5)$. Significance across control was indicated with an asterisk at $P<0.05$. 


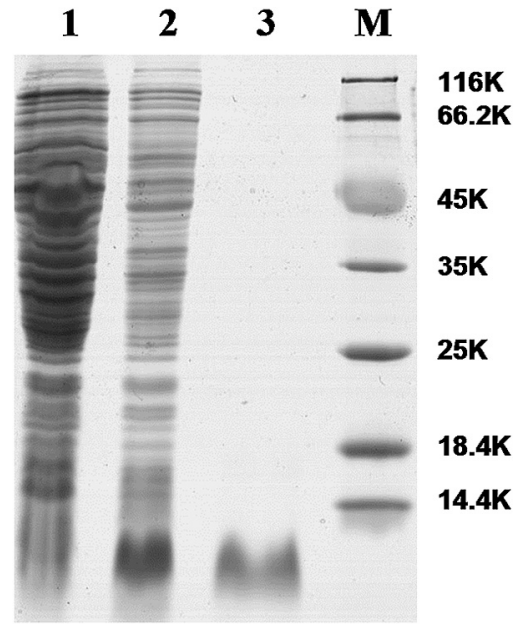

Fig. 4. SDS-PAGE analysis of the recombinant VpDef. The gel was visualized by CBBR250 staining. Lane 1: lysates of $E$. coli transformed with plasmid pET-30a-VpDef (without induction); lane 2: lysates of E. coli transformed with plasmid pET-30aVpDef (induction); lane 3: purified rVpDef; lane M: protein molecular standard.

most cells showed low values of permeability and relatively high values of MP, appearing in the lower right quadrant of the display (Q4; 95.9\%). After treated with nisin $\mathrm{Z}$ for $30 \mathrm{~min}$ at concentration of $1 \times$ MIC (Fig. 8 B), over $98 \%$ of the total cells lost MP and became permeable to TO-PRO-3 (Q1). In cultures treated with rVpDef (Fig. 8C and D), the proportion of low-MP cells (Q1 + Q3) increased with increasing concentrations of the peptide, and notable changes of membrane permeability (Q1 + Q2) were observed. Over 39.2\% of total $M$. luteus became permeable to TO-PRO-3 (Q1) when exposed to rVpDef at $3 \times$ MIC.

\subsection{Alternations in surface morphology of bacterial cells}

SEM experiment was performed to gain insight into the direct effect of rVpDef on the morphology of $M$. luteus. Untreated bacteria display a smooth surface, with no apparent cellular debris (Fig. 9A). In contrast, the exposure of bacteria to rVpDef for up to $1 \mathrm{~h}$ induced a remarkable modification of their surface morphology. These include deep roughening of the cell surface and the formation of blebs (Fig. 9B-D). At $10 \times$ MIC of rVpDef, lysed bacteria were frequently observed, which seemed to have lost their contents and became flat (Fig. 9E and F).

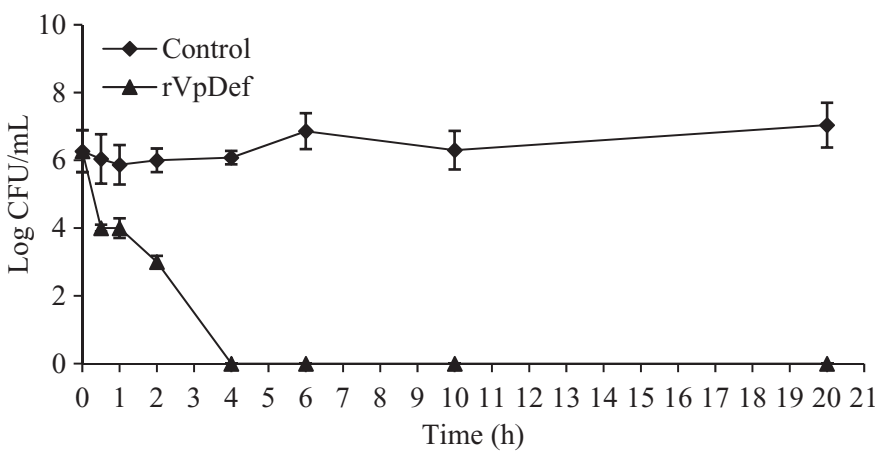

Fig. 5. Time kill experiment of rVpDef for M. luteus. M. luteus cells $\left(2 \times 10^{7}\right)$ were grown in LB at $37^{\circ} \mathrm{C}$, diluted in $10 \mathrm{mM}$ sodium phosphate buffer ( $\mathrm{pH} 7.4$ ) and incubated with $10 \times \mathrm{MIC}$ of $\mathrm{rVpDef}$ at $37^{\circ} \mathrm{C}$. The numbers of surviving cells were counted and the time-kill curves were plotted with time against the logarithm of the viable count. Triple independent experiments were performed. $\bullet$ : M. luteus culture with PBS; : M. luteus culture with $10 \times \mathrm{rVpDef}$.
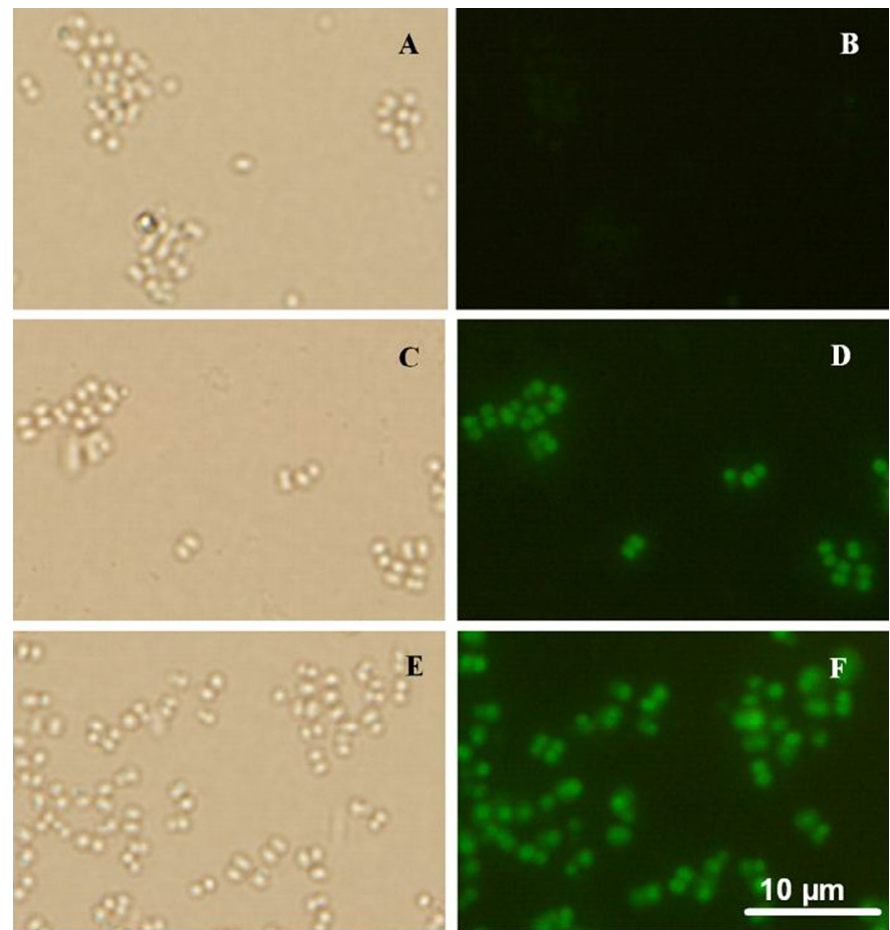

Fig. 6. M. luteus membrane permeation induced by rVpDef and visualized by FITC fluorescence. $M$. luteus cells were grown as indicated in Fig. 5, incubated with $2 \times$ and $10 \times$ MIC of rVpDef at $37^{\circ} \mathrm{C}$ for $1 \mathrm{~h}$, and immobilized on poly-L-lysine-treated glass slides. FITC $\left(6 \mu \mathrm{g} \mathrm{ml}^{-1}\right.$ in PBS) was spread on the slides and incubated at $37^{\circ} \mathrm{C}$ for $1 \mathrm{~h}$. PBS was used as negative control. After washing, phase contrast images as well as images under fluorescence light were recorded using an Olympus BX51 fluorescence microscope. (A) Phase-contrast images of mock (PBS only)-treated bacteria; (B) fluorescent images of mock (PBS only)-treated bacteria; (C, E) phase-contrast images of bacteria treated with $2 \times$ and $10 \times$ MIC of rVpDef, respectively; (D, F) fluorescent images of bacteria treated with $2 \times$ and $10 \times$ MIC of rVpDef, respectively. M. luteus was visualized with an oil-immersion objective $(\times 100)$.

\section{Discussion}

Humoral immunity in marine invertebrates is characterized by antimicrobial agents present in the hemolymph, among which AMPs play an important role in the host innate immune response (Tincu and Taylor, 2004). Many AMPs have been identified and characterized in marine mollusks up to now. However, there is far fewer molecular characterization and functional studies on AMPs in Manila clam $V$. philippinarum as compared to those in mussels and oysters.

$V p D e f$ gene expression in response to microbial challenge was performed to gain insight into the role of VpDef in clam immunity. The transcriptional level of $V p D e f$ was up-regulated significantly in hemocytes by $48 \mathrm{~h}$ post infection (except at $24 \mathrm{~h}$ ), with the highest expression level (1300-fold) detected at $12 \mathrm{~h}$ post-infection. The drastic increase of VpDef in the early stage might be ascribed to considerable recruitment of VpDef-producing hemocytes into circulating system. Allam et al. (2006) reported a rapid increase (within $72 \mathrm{~h}$ ) of circulating hemocytes in V. philippinarum after injection of Vibrio tapetis and $V$. anguillarum. In general, expression of marine mollusk defensin transcripts is known to be induced by bacterial challenges (Adhya et al., 2012; De Zoysa et al., 2010; Rosa et al., 2011; Zhao et al., 2007, 2010). However, there are some reports of decreased transcriptional responses of mollusk defensins against bacterial infection. For example, the expression of $\mathrm{Cg}$-defh2 (Gonzalez et al., 2007) and MGD2 (Mitta et al., 2000) in hemocytes were significantly decreased after bacterial challenge. VpDef transcription level was also sharply decreased in hemocytes at $24 \mathrm{~h}$ post-infection. This may be due to the mobilization effect 

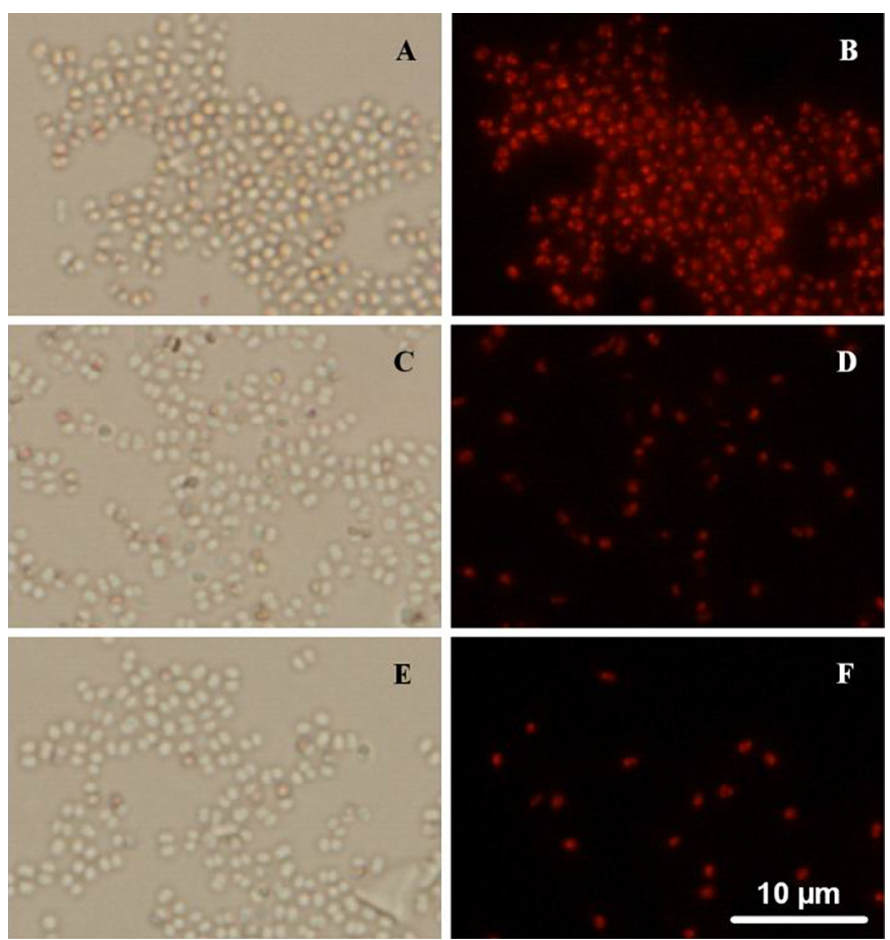

Fig. 7. M. luteus viability affected by rVpDef and visualized by CTC fluorescence. Cells were grown, treated with $2 \times$ and $10 \times$ MIC of rVpDef, stained with CTC $(5 \mathrm{mM}$ in $\mathrm{PBS}$ ), and detected by Olympus BX51 fluorescence microscope as indicated in the legend of Fig. 6. (A) Phase-contrast images of mock (PBS only)-treated bacteria; (B) fluorescent images of mock (PBS only)-treated bacteria; (C, E) phase-contrast images of bacteria treated with $2 \times$ and $10 \times$ MIC of rVpDef, respectively; (D, F) fluorescent images of bacteria treated with $2 \times$ and $10 \times$ MIC of rVpDef, respectively. M. luteus was visualized with an oil-immersion objective $(\times 100)$.

ofVpDef-producing hemocytes to the bacterial colonization or infected sites, and/or apoptosis phenomena affecting relevant hemocytes (De Zoysa et al., 2010; Gonzalez et al., 2007; Mitta et al., 1999, 2000). All these results suggested that VpDef had an important function in host defense against invasive pathogens.

The tissue distribution of VpDef mRNA and its relative peptide were examined by using RT-PCR and immunohistochemical analyses, respectively. The RT-PCR results indicated a high expression level in hemocytes, moderate in mantles and low expression level in gills and hepatopancreas, which was confirmed by the immunolocalization analysis. Similarly, Cg-defh2 has been reported to be constitutively expressed in hemocytes (Gonzalez et al., 2007). Mussel defensins (MGD1 and MGD2) were solely produced in hemocytes, where they were stored and released following bacterial challenges (Mitta et al., 1999, 2000). As concerned to CgDefm (Gueguen et al., 2006) and abalone defensin (De Zoysa et al., 2010), the highest constitutive expression was found in the tissue of mantle. It was noteworthy that MCdef, another defensin in Manila clam, was dominantly expressed in the adductor muscle (Adhya et al., 2012). It was suggested that the specific distribution of marine mollusk defensins could be partially explained by their spatial involvement of microbicidal activity in different tissues of the organisms.

It is of prime importance to understand the microbicidal activities of VpDef in vitro. rVpDef showed relatively good microbicidal activity against $M$. luteus, but was less effective to Staphyloccocus aureus and Gram-negative bacteria. Compared to standard antibiotics (Table 2) and other mollusks defensins, the inhibitory activity of VpDef was much weaker. The MIC of mussel and oyster defensins toward different bacteria ranged from 0.01 to $40 \mu \mathrm{M}$ (Charlet et al., 1996; Schmitt et al., 2010). In addition, when Micrococcus lysodeikticus was incubated with $10 \times$ MIC of Cg-Defm, all bacteria were killed within a few minutes (Gueguen et al., 2006). However, $4 \mathrm{~h}$ was required for $\mathrm{rVpDef}(10 \times \mathrm{MIC})$ to kill all cells after initial treatment. In the present studies, rVpDef perhaps undergoes disulfide shuffling during the refolding processes, and thus results in different protein species with unnatural disulfide bonds. Moreover, the 6-histidine C-terminal prolongation in the rVpDef perhaps also affects the antimicrobial activity.

Several defensins had been reported to damage bacterial and artificial membranes, including mammalian $\alpha$ - and $\beta$-defensins (Hadjicharalambous et al., 2008; Sugiarto and Yu, 2007), as well as arthropod defensins (Cociancich et al., 1993; Nakajima et al., 2003). However, no membrane-disruptive effect had been reported in mollusk defensins so far. In the present study, deleterious effects of rVpDef on the bacterial membrane of $M$. luteus were investigated by monitoring membrane potential and permeability. Compared with the pore-forming peptide nisin $\mathrm{Z}$, rVpDef $(1 \times$ and $3 \times$ MIC) induced a similar decrease of MP and notable changes of membrane permeability. These results supported the hypothesis that the bacterial membrane was one of the potential targets of VpDef induced toxicity. In marked contrast, oyster $\mathrm{Cg}$-Defs even at lethal concentrations $(10 \times \mathrm{MIC})$ did not compromise the membrane integrity of bacteria, but inhibited peptidoglycan biosynthesis by binding to lipid II (Schmitt et al., 2010). Likewise, Schneider et al. (2010) recently demonstrated that a fungal defensin (plectasin) exhibited a similar mechanism of action. In the present study, SEM experiment revealed that $\mathrm{rVpDef}$ induced a remarkable modification of cell surface morphology, while the original ball shape was still recognizable (Fig. 9). This was also in agreement with the fluorescence microscopy data (Figs 6 and 7). However, treatment of Bacillus subtilis with plectasin induced severe cell shape deformations (Schneider et al., 2010), which indicated the different modes of action for plectasin compared with rVpDef.
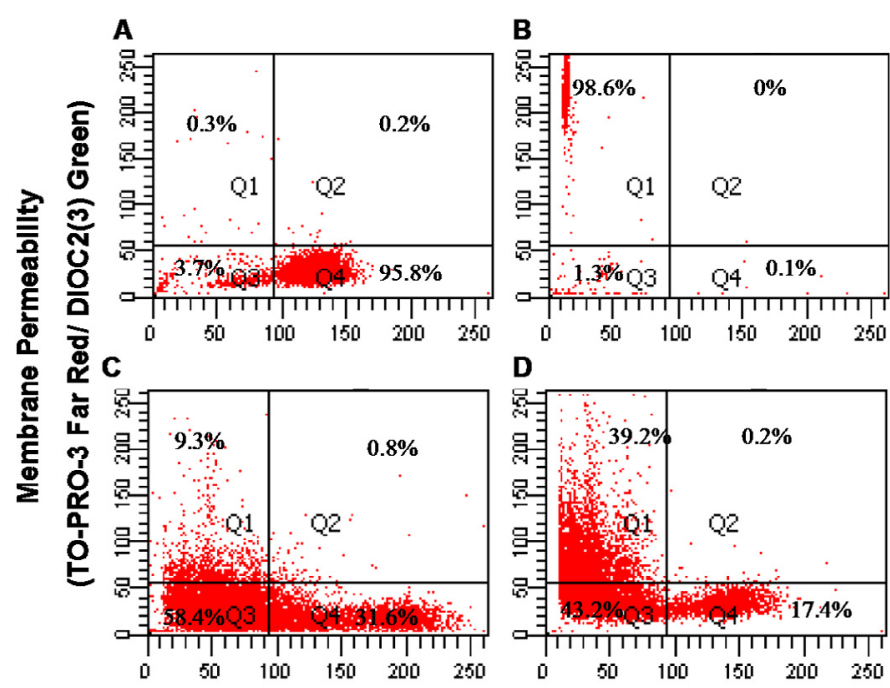

\section{Membrane Potential (DiOc2(3) Red/Green)}

Fig. 8. Flow cytometric studies of membrane potential and permeability of $M$. luteus after exposed to $1 \times$ and $3 \times$ MIC of rVpDef for 30 minutes. M. luteus cells were prepared as indicated in Fig. 5, and diluted in PBS ( $\mathrm{pH}$ 7.4) buffer to the concentration of $10^{6}-10^{7}$ cells $/ \mathrm{ml}$. After exposure to rVpDef at $1 \times$ and $3 \times \mathrm{MIC}$ for $30 \mathrm{~min}$ at $37^{\circ} \mathrm{C}$, the cells were incubated with $30 \mu \mathrm{M} \mathrm{DiOC}_{2}$ (3) and $100 \mathrm{nM}$ TO-PRO-3 at room temperature for $10 \mathrm{~min}$. PBS was used as negative control and the pore-forming lantibiotic nisin $\mathrm{Z}(1.5 \mu \mathrm{g} / \mathrm{ml}$ corresponds to $1 \times \mathrm{MIC})$ was used as positive control. The ratio of red to green fluorescence of $\mathrm{DiOC2}(3)$ provides a measurement of bacterial MP, and the ratio of TO-PRO-3 fluorescence to DiOC2(3) green fluorescence produces an indicator of membrane permeability. (A) PBS; (B) nisin Z; (C) $1 \times$ MIC rVpDef; (D) $3 \times$ MIC rVpDef. 

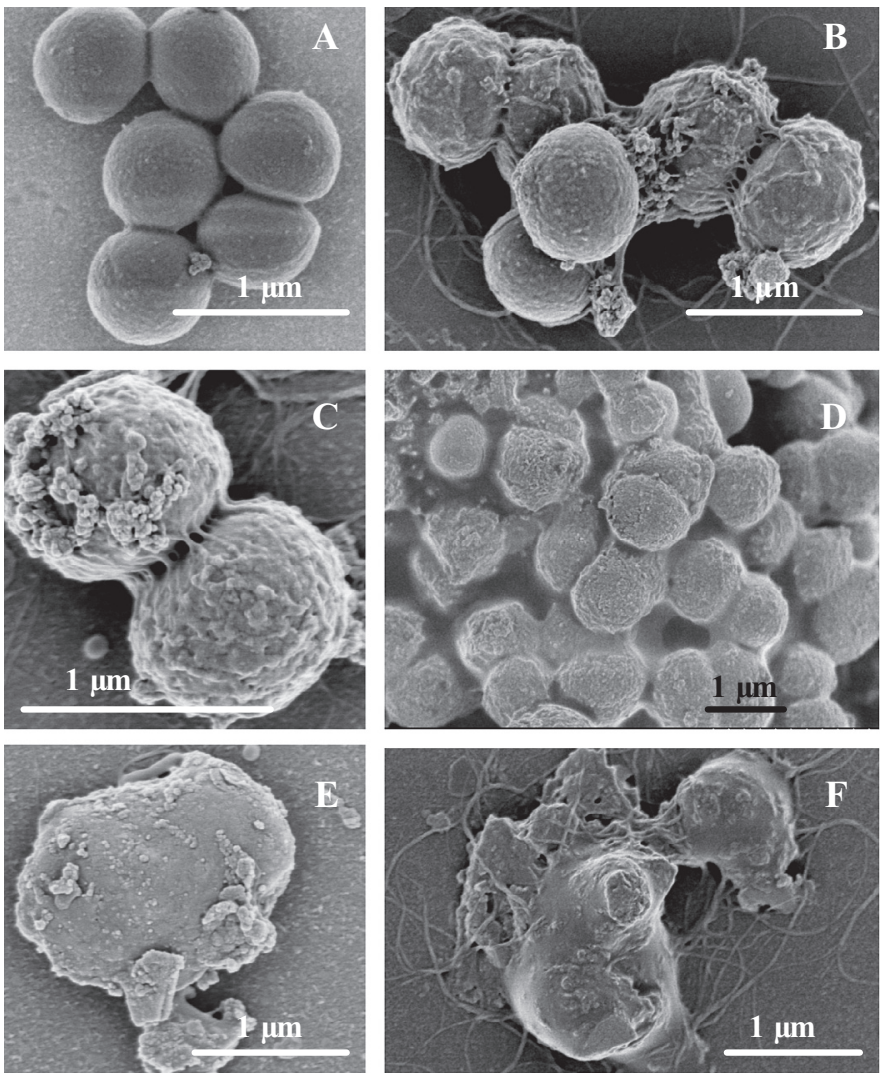

Fig. 9. SEM of rVpDef-treated M. luteus. Cells were grown, treated with $2 \times$ and $10 \times$ MIC of rVpDef for $1 \mathrm{~h}$ at $37^{\circ} \mathrm{C}$, and immobilized on poly-L-lysine-treated glass slides. Slide-immobilized cells were fixed with $2.5 \%(\mathrm{w} / \mathrm{v})$ glutaraldehyde in $0.1 \mathrm{M}$ sodium phosphate buffer for $30 \mathrm{~min}$ and dehydrated with a graded ethanol series. After critical-point drying and gold coating, the samples were visualized by Hitachi S-4800 instrument. (A) Control bacteria; (B, C) bacteria after treatment with $2 \times$ MIC of rVpDef for $1 \mathrm{~h}$; (D, E and F) bacteria after treatment with $10 \times$ MIC of rVpDef for $1 \mathrm{~h}$.

Schmitt et al. (2010) surmised that invertebrate defensins, and more generally $\mathrm{CS} \alpha \beta$-containing defensins were specific inhibitors of a bacterial biosynthesis pathway rather than mere membrane active agents. Interestingly, four residues proposed to be involved in the binding of oyster defensins and plectasin to lipid II (Schmitt et al., 2010; Schneider et al., 2010) were conserved in VpDef (Phe ${ }^{2}$, Gly $^{3}$, Cys ${ }^{4}$ and Cys $^{26}$, Fig. 2A), indicating that VpDef may also be involved in lipid II binding (yet unidentified). Similar to Nisin Z, which combines pore-forming and lipid II-trapping activities (Wiedemann et al., 2001), VpDef may possess multiple or complementary mechanisms of action to kill bacteria. Further investigation of the ability of VpDef to disrupt membranes and inhibit peptidoglycan biosynthesis is needed to fully elucidate mechanisms of action.

\section{Acknowledgements}

This research was supported by grants from NSFC (41476126), the Key Research Program of the Chinese Academy of Sciences (Grant No. KZZD-EW-14) and the Strategic Priority Research Program of the Chinese Academy of Sciences (XDA11020405).

\section{Appendix: Supplementary material}

Supplementary data to this article can be found online at doi:10.1016/j.dci.2015.02.009.

\section{References}

Adhya, M., Jeung H.D., Kang H.S., Choi, K.S., Lee, D.S., Cho, M., 2012. Cloning and localization of MCdef, a defensin from Manila clams (Ruditapes philippinarum). Comp. Biochem. Physiol. 161B, 25-31.

Allam, B., Paillard, C., Auffret, M., Ford, S.E., 2006. Effects of the pathogenic Vibrio tapetis on defence factors of susceptible and non-susceptible bivalve species: II. Cellular and biochemical changes following in vivo challenge. Fish Shellfish Immunol. 20, 384-397.

Ammerman, J.W., Fuhrman, J.A., Hagstrom, A., Azam, F. 1984. Bacterioplankton growth in seawater: I. Growth kinetics and cellular characteristics in seawater cultures. Mar. Ecol. Prog. Ser. 18, 31-39.

Amsterdam, D., 1996. Susceptibility testing of antimicrobials in liquid media. In: Loman, V. (Ed.), Antibiotics in Laboratory Medicine, 4th ed. Williams and Wilkins, Baltimore, MD, pp. 52-111.

Bachere, E., Gueguen, Y., Gonzalez, M., de Lorgeril, J., Garnier, J., Romestand, B., 2004. Insights into the antimicrobial defense of marine invertebrates: the penaeid shrimps and the oyster Crassostrea gigas. Immunol. Rev. 198, 149-168.

Brogden, K.A., 2005. Antimicrobial peptides: pore formers or metabolic inhibitors in bacteria? Nature 3, 238-250.

Bulet, P., Stocklin, R., 2005. Insect antimicrobial peptides: structures, properties and gene regulation. Protein Pept. Lett. 12, 3-11.

Bulet, P., Stocklin, R., Menin, L., 2004. Anti-microbial peptides: from invertebrates to vertebrates. Immunol. Rev, 198, 169-184.

Charlet, M., Chernysh, S., Philippe, H., Hetru, C., Hoffmann, J.A., Bulet, P., 1996. Isolation of several cysteine-rich antimicrobial peptides from the blood of mollusc Mytilus edulis. J. Biol. Chem. 271, 21808-21813.

Cheng, S.F., Zhan, W.B., Xing, J., Sheng, X.Z., 2006. Development and characterization of monoclonal antibody to the lymphocystis disease virus of Japanese flounder Paralichthys olivaceus isolated from China. J. Virol. Methods 135, 173-180.

Cociancich, S., Ghazi, A., Hetru, C. Hoffmann, J.A., Letellier, L., 1993. Insect defensin, an inducible antibacterial peptide, forms voltage-dependent channels in Micrococcus luteus. J. Biol. Chem. 268, 19239-19245.

De Zoysa, M.D., Whang, I., Lee, Y., Lee, S., Lee, J.S., Lee, J., 2010. Defensin from disk abalone Haliotis discus discus: molecular cloning, sequence characterization and immune response against bacterial infection. Fish Shellfish Immunol. 28, 261266.

Diamond, G., Beckloff, N., Weinberg, A., Kisich, K.O., 2009. The role of antimicrobial peptides in innate host defense. Curr. Pharm. Des. 15, 2377-2392.

Dimarcq, J., Bulet, P., Hetru, C., Hoffmann, J., 1998. Cysteine-rich antimicrobial peptides in invertebrates. Biopolymers 47, 465-477.

Ganz, T., 2003. Defensins: antimicrobial peptides of innate immunity. Nat. Rev. Immunol. 3, 710-720.

Gonzalez, M., Gueguen, Y., Desserr, E.G., de Lorgeril, J., Romestand, B., Bachere, E., 2007. Molecular characterization of two isoforms of defensin from hemocytes of the oyster Crassostrea gigas. Dev. Comp. Immunol. 31, 332-339.

Gueguen, Y., Herpin, A., Aumelas, A., Garnier, J., Fievet, J., Escoubas, J.M., et al., 2006 Characterization of a defensin from the oyster Crassostrea gigas: recombinant production, folding, solution structure, antimicrobial activities and gene expression. J. Biol. Chem. 281, 313-323.

Hadjicharalambous, C., Sheynis, T., Jelinek, R., Shanahan, M.T., Ouellette, A.J., Gizeli, E., 2008. Mechanisms of $\alpha$-defensin bactericidal action: comparative membrane disruption by cryptdin-4 and its disulfide-null analogue. Biochemistry 47 , $12626-12634$.

Hale, J.D., Hancock, R.E., 2007. Alternative mechanisms of action of cationic antimicrobial peptides on bacteria. Expert Rev. Anti Infect. Ther. 5, 951-959.

Hubert, F., Noel, T., Roch, P., 1996. A member of the arthropod defensin family from edible Mediterranean mussels (Mytilus galloprovincialis). Eur. J. Biochem. 240, 302-306.

Kenneth, J.L., Thomas, D.S., 2001. Analysis of relative gene expression data using real time quantitative PCR and the $2^{-\Delta \Delta C t}$ method. Method 25, 402-408.

Mangoni, M.L., Papo, N., Barra, D., Simmaco, M., Bozzi, A., Glulio, A.D., et al., 2004. Effects of the antimicrobial peptide temporin L on cell morphology, membrane permeability and viability of Escherichia coli. Biochem. J. 380, 859-865.

Mitta, G., Vandenbulcke, F., Hubert, F., Roch, P., 1999. Mussel defensins are synthesized and processed in granulocytes then released into the plasma after bacterial challenge. J. Cell Sci. 112, 4233-4242.

Mitta, G., Hibert, F., Dyrynda, E.A., Boudry, P., Roch, P., 2000. Mytilin B and MGD2, two antimicrobial peptides of marine mussels: gene structure and expression analysis. Dev. Comp. Immunol. 24, 381-393.

Nakajima, Y., Ishibashi, J., Yukuhiro, F., Asaoka, A., Taylor, D., Yamakawa, M., 2003. Antibacterial activity and mechanism of action of tick defensin against Grampositive bacteria. Biochim. Biophys. Acta 1624, 125-130.

Novo, D., Perlmutte, N.G., Hunt, R.H., Shapiro, H.M., 1999. Accurate flow cytometric membrane potential measurement in bacteria using diethyloxacarbocyanine and a ratiometric technique. Cytometry 35, 55-63.

Novo, D.J., Perlmutter, N.G., Hunt, R.H., Shapiro, H.M., 2000. Multiparameter flow cytometric analysis of antibiotic effects on membrane potential, membrane permeability, and bacterial counts of Staphylococcus aureus and Micrococcus luteus. Antimicrob. Agents Chemother. 44, 827-834.

Otero-González, A.J., Magalhães, B.S., Garcia-Villarino, M., López-Abarrategui, C., Sousa, D.A., Dias, S.C., et al., 2010. Antimicrobial peptides from marine invertebrates as a new frontier for microbial infection control. FASEB J. 24, 1320-1334.

Park, K.I., Paillard, C., Chevalier, P.L., Choi, K.S., 2006. Report on the occurrence of brown ring disease (BRD) in Manila clam, Ruditapes philippinarum, on the west coast of Korea. Aquaculture 255, 610-613. 
Rosa, R.D., Santini, A., Fievet, J., Bulet, P., Destoumieux-Garzon, D., 2011. Big defensins, a diverse family of antimicrobial peptides that follows different patterns of expression in hemocytes of the oyster Crassostrea gigas. PLoS ONE 6, e25594.

Schmitt, P., Wilmes, M., Pugnière, M., Aumelas, A., Bachère, E., Sahl, H.G., et al., 2010. Insight into invertebrate defensin mechanism of action: oyster defensins inhibit peptidoglycan biosynthesis by binding to lipid II. J. Biol. Chem. 38, 2920829216.

Schneider, T., Kruse, T., Wimmer, R., Wiedemann, I., Sass, V., Pag, U., et al., 2010. Plectasin, a fungal defensin, targets the bacterial cell wall precursor lipid II. Science $328,1168-1172$.

Seo, J.K., Crawford, J.M., Stone, K.L., Noga, E.J., 2005. Purification of a novel arthropod defensin from the American oyster, Crassostrea virginica. Biochem. Biophys. Res. Commun. 338, 1998-2004.

Smith, J.J., McFeters, G.A., 1997. Mechanisms of INT (2-(4-iodophenyl)-3-(4nitrophenyl)-5-phenyl tetrazolium chloride), and CTC (5-cyano-2,3-ditolyltetrazolium chloride) reduction in Escherichia coli K-12. J. Microbiol. Methods $29,161-175$.

Sperstad, S.V., Haug, T., Blencke, H.M., Styrvold, O.B., Li, C., Stensvåg, K., 2011. Antimicrobial peptides from marine invertebrates: challenges and perspectives in marine antimicrobial peptide discovery. Biotechnol. Adv. 29, 519-530.

Sugiarto, H., Yu, P.L., 2007. Mechanisms of action of ostrich beta-defensins against Escherichia coli. FEMS Microbiol. Lett. 270, 195-200.

Tincu, J.A., Taylor, S.W., 2004. Antimicrobial peptides from marine invertebrates. Antimicrob. Agents Chemother. 48, 3645-3654.
Wang, Q., Zhang, L., Zhao, J., You, L., Wu, H., 2012. Two goose-type lysozymes in Mytilus galloprovincialis: possible function diversification and adaptive evolution. PLOS ONE 7 (9), e45148.

Wiedemann, I., Breukink, E., van Kraaij, C., Kuipers, O.P., Bierbaum, G., de Kruijff, B. et al., 2001. Specific binding of nisin to the peptidoglycan precursor lipid Il combines pore formation and inhibition of cell wall biosynthesis for potent antibiotic activity. J. Biol. Chem. 276, 1772-1779.

Wilm, M., Shevchenko, A., Houthaeve, T., Breit, S., Schweigerer, L., Fotsis, T., 1996. Femtomole sequencing of proteins from polyacrylamide gels by nano-electrospray mass spectrometry. Nature 379, 466-469.

Wong, J.H., Xia, L., Ng, T.B., 2007. A review of defensins of diverse origins. Curr. Protein Pept. Sci. 8, 446-459.

Yang, J.L., Wang, L.L., Zhang, H.A., Qiu, L.M., Wang, H., Song, L.S., 2011. C-type lectin in Chlamys farreri (CfLec-1) mediating immune recognition and opsonization. PLoS ONE 6, e17089.

Yang, Y.S., Mitta, G., Chavanieu, A., Calas, B., Sanchez, J.F., Roch, P., et al., 2000. Solution structure and activity of the synthetic four-disulfide bond Mediterranean mussel defensin (MGD-1). Biochemistry 39, 14436-14447.

Zasloff, M., 2002. Antimicrobial peptides of multicellular organisms. Nature 415 389-395.

Zhao, J., Song, L., Li, C., Ni, D., Wu, L., Zhu, L., et al., 2007. Molecular cloning, expression of a big defensin gene from bay scallop Argopectin irradians and the antimicrobial activity of its recombinant protein. Mol. Immunol. 44, 360-368.

Zhao, J., Li, C., Chen, A., Li, L., Su, X., Li, T., 2010. Molecular characterization of a novel big defensin from clam Venerupis philippinarum. PLoS ONE 5, e13480. 